\title{
Expression of programmed cell death-ligand 1 in primary testicular diffuse large $B$ cell lymphoma: A retrospective study
}

\author{
DONGDONG ZHU ${ }^{1 *}, \mathrm{JUN}_{\mathrm{ZHU}}{ }^{*}$, WEI YU ${ }^{1 *}$, PENG HONG $^{1}, \mathrm{YU} \mathrm{FAN}^{1}, \mathrm{ZHONGYUAN} \mathrm{ZHANG}^{1}$, \\ JUN LI ${ }^{2}$, QUN HE ${ }^{2}$, WENKE HAN ${ }^{1}$, CHENG SHEN ${ }^{1}$ and JIE JIN ${ }^{1}$ \\ ${ }^{1}$ Department of Urology, Peking University First Hospital, Institute of Urology, Peking University, \\ National Urological Cancer Center; ${ }^{2}$ Department of Pathology, Peking University First Hospital, Beijing 100034, P.R. China
}

Received September 14, 2018; Accepted May 17, 2019

DOI: $10.3892 / 01.2019 .10595$

\begin{abstract}
The present study evaluated programmed cell death-ligand 1 (PD-L1) expression in tumor cells and in the tumor microenvironment (TME) and its association with clinical data in primary testicular diffuse large B cell lymphoma (DLBCL). PD-L1 was determined by immunohistochemistry in 30 patients with primary testicular DLBCL and assessed for associations with clinical characteristics, progression-free survival (PFS) and overall survival (OS). The mean patient age was 62.2 years. Overall, 10 (33.3\%) patients had advanced-stage (stage III/IV) disease and 14 (46.7\%) patients had an International Prognostic Index (IPI) of $\geq 3$. The median follow-up time following orchiectomy was 23.5 months. During this time, $10(33.3 \%)$ patients experienced disease progression and $11(36.7 \%)$ patients succumbed. PD-L1 expression in tumor cells and in the TME was detected in 20 (66.7\%) and 13 (43.3\%) patients, respectively. PD-L1 expression on tumor cells and in the TME was higher in those at an early stage compared with patients with an advanced stage of disease $(\mathrm{P}=0.045$ and
\end{abstract}

Correspondence to: Dr Cheng Shen or Dr Jie Jin, Department of Urology, Peking University First Hospital, Institute of Urology, Peking University, National Urological Cancer Center, 8 Xishiku Street, Xicheng, Beijing 100034, P.R. China

E-mail: shencheng@263.net

E-mail: 18810534177@163.com

${ }^{*}$ Contributed equally

Abbreviations: BCL-2, B cell leukemia 2; $\beta 2-\mathrm{MG}, \beta_{2}$-microglobulin; CNS, central nervous system; DLBCL, diffuse large B cell lymphoma; GCB, germinal center B cell-like; IPI, International Prognostic Index; LDH, lactate dehydrogenase; NHL, non-Hodgkin lymphoma; non-GCB, non-germinal center B cell-like; OS, overall survival; PD-1, programmed cell death 1; PD-L1, programmed cell death-ligand 1; PFS, progression-free survival; PT-DLBCL, primary testicular DLBCL; PTL, primary testicular lymphoma; RT, radiotherapy; TME, tumor microenvironment

Key words: primary testicular lymphoma, primary testicular diffuse large B cell lymphoma, programmed cell death-ligand 1
0.017, respectively). In addition, PD-L1 expression in tumor cells was higher in patients with a low IPI compared with those with a high IPI ( $\mathrm{P}=0.019)$. A Kaplan-Meier analysis identified no association of PD-L1 expression on tumor cells with PFS $(\mathrm{P}=0.763)$ or $\mathrm{OS}(\mathrm{P}=0.531)$, or of $\mathrm{PD}-\mathrm{L} 1$ expression in the TME with PFS $(\mathrm{P}=0.572)$ or OS $(\mathrm{P}=0.934)$. The present study demonstrated that PD-L1 expression in tumor cells and in the TME was higher in patients at an early stage of disease compared with those at an advanced stage, and that PD-L1 expression on tumor cells was higher in patients with a low IPI than in those with a high IPI. Furthermore, PD-L1 expression in tumor cells and in the TME was not associated with PFS or OS.

\section{Introduction}

Primary testicular lymphoma (PTL) is an uncommon and aggressive form of extranodal non-Hodgkin lymphoma (NHL) (1). PTL is the most common testicular malignancy in men $>60$ years of age (2). PTL accounts for $<5 \%$ of testicular malignancies and 1-2\% of NHL (3). Overall, $60-79 \%$ of patients present with an early stage of disease (stage I/II), but the outcome is poor (4). In recent years, immunotherapy has become a promising and effective treatment strategy for several types of malignancy.

Programmed cell death-ligand 1 (PD-L1), also known as B7-H1 or CD274, is an inhibitory ligand of programmed cell death 1 (PD-1). PD-L1 is expressed on the surface of tumor cells, $\mathrm{T}$ cells and other immune cells $(5,6)$. The binding of PD-L1 to PD-1 suppresses the activation and effector function of T cells, thereby inducing T-cell exhaustion and functioning as a crucial checkpoint in the regulation of cellular and humoral immune responses (7-9). Targeting the PD-1/PD-L1 signaling pathway has marked clinical therapeutic efficacy, not only in solid tumors (10) but also in Hodgkin lymphoma and NHL $(11,12)$.

PTL, characterized by tumors arising in an immune-privileged site and under the selective pressure of immune surveillance, may develop an immune escape phenotype (13). Furthermore, a nascent PTL clone may benefit from developing in an immune-privileged site behind the blood-testis barrier (14). Genetic alterations in 9p24.1, resulting in increased expression of PD-L1, have been demonstrated in PTL (15). Diffuse large B cell lymphoma (DLBCL), the predominant histopathological type of PTL, accounts for $80-98 \%$ of PTL 
cases (16). Previous studies have reported the expression of PD-L1 in DLBCL $(17,18)$; however, studies of PD-L1 expression in primary testicular DLBCL (PT-DLBCL) are lacking. In the present study, the expression of PD-L1 in PT-DLBCL was investigated retrospectively. Using a well-annotated cohort of patients, the immunohistochemical expression of PD-L1 on tumor cells and in the tumor microenvironment (TME) was evaluated, and its association with clinical data was analyzed.

\section{Materials and methods}

Patients and samples. In total, 30 patients, aged 33-66 years, were diagnosed with PT-DLBCL at Peking University First Hospital (Beijing, China) between August 2006 and July 2017, and were included in the present study. Patients with clear pathological diagnosis and complete clinical data were included in the study, and patients whose pathological diagnosis was not PT-DLBCL and whose clinical data were incomplete were excluded. All patients underwent orchiectomy for pathological diagnosis. Formalin-fixed paraffin-embedded blocks from 30 PT-DLBCL specimens were retrieved from the Department of Urological Pathology, Peking University First Hospital. Clinicopathological and follow-up data were collected and entered into a database. The Ann Arbor staging classification system was used for staging, and the International Prognostic Index (IPI) was used for risk stratification (14). The algorithm of Hans et al (19) was used to determine germinal center or non-germinal center classification. Immunohistochemistry was used to determine the expression of B cell leukemia 2 (BCL-2). BCL-2 expression was assessed by BCL-2 score. The scoring criteria were: 0 points (no lymphoma cells stained); 1 point (1-10\% stained lymphoma cells); 2 points (11-30\%); 3 points (31-70\%); and 4 points ( $>70 \%)$ (20). Pathologists determined the $\mathrm{BCl}-2$ score as part of the postoperative pathology to determine PT-DLBCL diagnosis, and the BCL-2 scores were collected from postoperative pathology reports of the patients. Overall survival (OS) was calculated from the time of diagnosis to the time of mortality or the last follow-up. Progression-free survival (PFS) was calculated from the time of diagnosis to the time of disease progression, mortality or the last follow-up. The study was approved by the Ethics Committee of Peking University First Hospital [(Beijing, China); ethics no., 2018 (197)]. A waiver of written informed consent was granted from the Ethics Committee of Peking University First Hospital, since the study was a retrospective analysis of routine data.

Immunohistochemistry. All tumor specimens were acquired by orchiectomy prior to chemotherapy and radiotherapy (RT). The expression of PD-L1 in the PT-DLBCL samples was evaluated according to standard immunohistochemistry protocols. Briefly, $4 \mu \mathrm{m}$-thick sections from formalin-fixed paraffin-embedded specimens were deparaffinized in xylene, rehydrated in decreasing concentrations of ethanol (100, 95, 95 and $85 \%$ ) and washed in distilled water. Heat-induced antigen retrieval at $120^{\circ} \mathrm{C}$ for $20 \mathrm{~min}$ was performed with Tris-EDTA buffer ( $\mathrm{pH} 8.0$ ). Following the use of $3 \%$ hydrogen peroxidase to block endogenous peroxidase, sections were incubated with $10 \%$ normal blocking serum in Tris-buffered saline at room temperature for $20 \mathrm{~min}$. The sections were then incubated with anti-human PD-L1 rabbit monoclonal antibody (1:50; E1L3N;
Cell Signaling Technology, Inc., Danvers, MA, USA) at $4^{\circ} \mathrm{C}$ for $16 \mathrm{~h}$, followed by incubation with the secondary antibody (goat anti-rabbit IgG/HRP polymer; PV-6001; OriGene Technologies, Inc., Beijing, China) at $37^{\circ} \mathrm{C}$ for $40 \mathrm{~min}$. Next, the sections were counterstained with hematoxylin at room temperature for $3 \mathrm{~min}$, dehydrated, covered with a coverslip and viewed under a light microscope (magnification, $\mathrm{x} 40$ ).

A total of two independent pathologists assessed the expression of PD-L1 on tumor cells and the expression of PD-L1 in the TME, without any prior knowledge of the clinical data of this cohort.

Positive PD-L1 expression on tumor cells was defined as $\geq 5 \%$ of lymphoma cells exhibiting distinct membranous and/or cytoplasmic staining for PD-L1, regardless of the PD-L1-positivity of nonmalignant stromal cells. Positive PD-L1 expression in the TME was defined as positive staining of stromal cells representing $\geq 20 \%$ of the total tissue (18).

Statistical analysis. The experiment was repeated 3 times. The data were expressed as the mean \pm standard deviation or $\mathrm{n}(\%)$ as appropriate. Patients were divided into subgroups according to the expression of PD-L1 on tumor cells or the expression of PD-L1 in the TME (positive or negative). The association of PD-L1 expression with clinicopathological characteristics was examined using Fisher's exact test. Survival curves for OS and PFS were prepared using the Kaplan-Meier method and analyzed using the log-rank test. SPSS software (version 14.0; SPSS, Inc., Chicago, IL, USA) was used for the statistical analysis of all data, and $\mathrm{P}<0.05$ was considered to indicate a statistically significant difference.

\section{Results}

Patient characteristics. The demographic and clinicopathological characteristics are presented in Table I. The study included 30 patients with a mean age of $62.2 \pm 15.0$ years (range, 33-66 years). Of these patients, $14(46.7 \%)$ had PTL in the left testicle, $12(40.0 \%)$ patients had PTL in the right testicle and $4(13.3 \%)$ patients had PTL in both testicles. Lactate dehydrogenase (LDH) was assessed in 21 patients, and $6(28.6 \%)$ had increased levels; $\beta_{2}$-microglobulin $(\beta 2-\mathrm{MG})$ was assessed in 13 patients, and 5 (38.5\%) had increased levels; 4 (13.3\%) of the 30 patients had B symptoms, including unexplained fever, drenching night sweats and weight loss $>10 \%$ of normal body weight; $10(33.3 \%)$ had advanced-stage (stage III/IV) disease; and $14(46.7 \%)$ had an IPI $\geq 3$. Inguinal orchiectomy was performed as a diagnostic procedure and initial treatment, and DLBCL was confirmed in all 30 patients following histopathological examination. Of 19 patients that were assessed for subtype, nine (47.4\%) had germinal center B cell-like (GCB) subtype disease and 10 (52.6\%) had non-GCB subtype disease. BCL-2 expression was assessed in 15 patients, with scores of $2-3$ in $6(40.0 \%)$ patients.

Treatments and outcomes. The final follow-up date was July 2018. The median follow-up time following orchiectomy was 23.5 months (range, 2-143 months). Disease progression occurred in $10(33.3 \%)$ patients; among these patients, one experienced central nervous system (CNS) relapse, and one experienced contralateral testis relapse. Overall, 
Table I. Demographic and clinicopathological characteristics of 30 patients with primary testicular diffuse large B cell lymphoma.

\begin{tabular}{|c|c|}
\hline Variable & $\mathrm{n}(\%)$ \\
\hline \multicolumn{2}{|l|}{ Age, years } \\
\hline$\leq 60$ & $12(40.0)$ \\
\hline$>60$ & $18(60.0)$ \\
\hline \multicolumn{2}{|l|}{ Laterality } \\
\hline Left & $14(46.7)$ \\
\hline Right & $12(40.0)$ \\
\hline Bilateral & $4(13.3)$ \\
\hline \multicolumn{2}{|l|}{$\mathrm{LDH}^{\mathrm{a}}, \mathrm{U} / 1$} \\
\hline$\leq 245$ & $15(71.4)$ \\
\hline$>245$ & $6(28.6)$ \\
\hline \multicolumn{2}{|c|}{$\beta 2-\mathrm{MG}^{\mathrm{b}}, \mathrm{mg} / \mathrm{l}$} \\
\hline$\leq 2.52$ & $8(61.5)$ \\
\hline$>2.52$ & $5(38.5)$ \\
\hline \multicolumn{2}{|c|}{ Clinical stage } \\
\hline I-II & $20(66.7)$ \\
\hline III-IV & $10(33.3)$ \\
\hline \multicolumn{2}{|l|}{ IPI } \\
\hline$<3$ & $16(53.3)$ \\
\hline$\geq 3$ & $14(46.7)$ \\
\hline \multicolumn{2}{|c|}{ GCB subtype ${ }^{c}$} \\
\hline Non-GCB & $10(52.6)$ \\
\hline GCB & $9(47.4)$ \\
\hline \multicolumn{2}{|c|}{ BCL-2 scored } \\
\hline $0-1$ & $9(60.0)$ \\
\hline $2-3$ & $6(40.0)$ \\
\hline \multicolumn{2}{|c|}{ 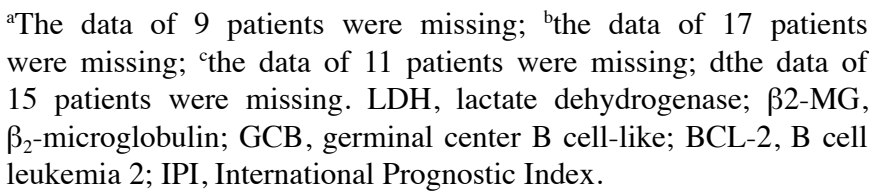 } \\
\hline
\end{tabular}

$11(36.7 \%)$ patients succumbed. Following orchiectomy, $23(76.7 \%)$ patients received chemotherapy, including a doxorubicin-containing regimen in all 23 patients and a rituximab-containing regimen in 15 patients. The median number of cycles was 6 (range, 1-8). A total of 11 patients received RT; 9 of these received RT at the contralateral testis alone, and 2 received $\mathrm{RT}$ at the contralateral testis and the abdominal lymph nodes. A total of 18 patients received CNS prophylaxis. In total, 10 patients received multimodal therapy (surgery+chemotherapy+radiotherapy+CNS prophylaxis) (Table II).

PD-L1 expression on tumor cells and in the TME. Among the 30 patients with PT-DLBCL, positive PD-L1 expression on tumor cells was detected in $20(66.7 \%)$, and a lack of PD-L1 expression on tumor cells was detected in 10 (33.3\%). Positive PD-L1 expression in the TME was detected in 13 patients
Table II. Treatments and outcomes of 30 patients with primary testicular diffuse large B cell lymphoma.

\begin{tabular}{|c|c|}
\hline Variable & $\mathrm{n}(\%)$ \\
\hline \multicolumn{2}{|c|}{ Chemotherapy } \\
\hline No & $7(23.3)$ \\
\hline Yes & $23(76.7)$ \\
\hline \multicolumn{2}{|c|}{ Rituximab ${ }^{\mathrm{a}}$} \\
\hline No & $8(34.8)$ \\
\hline Yes & $15(65.2)$ \\
\hline \multicolumn{2}{|c|}{ Radiotherapy } \\
\hline No & $19(63.3)$ \\
\hline Yes & $11(36.7)$ \\
\hline \multicolumn{2}{|c|}{ CNS prophylaxis } \\
\hline No & $12(40.0)$ \\
\hline Yes & $18(60.0)$ \\
\hline \multirow{3}{*}{\multicolumn{2}{|c|}{$\begin{array}{l}\text { Multimodal therapy } \\
\text { (surgery+chemotherapy+radiotherapy } \\
\text { +CNS prophylaxis) }\end{array}$}} \\
\hline & \\
\hline & \\
\hline No & $20(66.7)$ \\
\hline Yes & $10(33.3)$ \\
\hline \multicolumn{2}{|c|}{ Disease progression } \\
\hline No & $20(66.7)$ \\
\hline Yes & $10(33.3)$ \\
\hline \multicolumn{2}{|c|}{ Mortality } \\
\hline No & $19(63.3)$ \\
\hline Yes & $11(36.7)$ \\
\hline
\end{tabular}

(43.3\%), and a lack of PD-L1 expression in the TME was detected in 10 patients (56.7\%; Fig. 1). Among the 19 patients assessed for subtype, positive PD-L1 expression on tumor cells was detected in $5(55.6 \%)$ with the GCB subtype, and a lack of PD-L1 expression on tumor cells was detected in $4(44.4 \%)$ with the GCB subtype. Positive PD-L1 expression in the TME was detected in 3 patients $(33.3 \%)$ with the GCB subtype, and a lack of PD-L1 expression in the TME was detected in 6 patients $(66.7 \%)$ with the GCB subtype. Positive PD-L1 expression on tumor cells was detected in 8 patients $(80.0 \%)$ with the non-GCB subtype, and a lack of PD-L1 expression on tumor cells was detected in 2 patients $(20.0 \%)$ with the non-GCB subtype. Positive PD-L1 expression in the TME was detected in 5 patients $(50.0 \%)$ with the non-GCB subtype, and a lack of PD-L1 expression in the TME was detected in 5 patients (50.0\%) with the non-GCB subtype (Fig. 2).

Association of PD-L1 expression with clinicopathological characteristics. Overall, early-stage (stage I/II) and advanced-stage (stage III/IV) disease was identified in $20(66.7 \%)$ and 10 (33.3\%) patients, respectively. PD-L1 expression on tumor cells was significantly higher in patients at an early stage compared with those at an advanced stage $(16 / 20,80.0 \%$ vs. $4 / 10,40.0 \%$; 


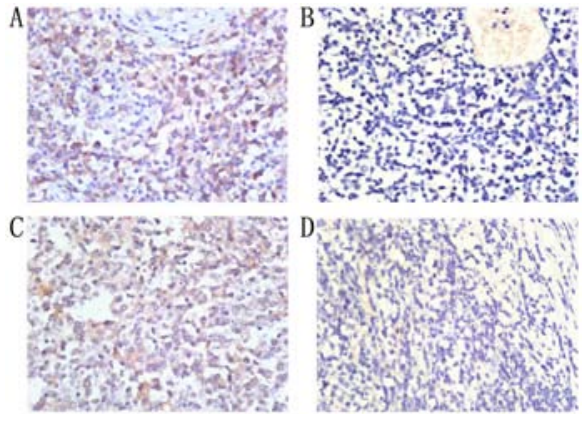

Figure 1. Immunohistochemical staining of PD-L1. (A) Positive expression and (B) lack of expression of PD-L1 in tumor cells; (C) positive expression and (D) lack of expression of PD-L1 in the TME. Magnification, $x 40$. PD-L1, programmed cell death ligand-1; TME, tumor microenvironment.

$\mathrm{P}=0.045$ ), and there was a significant difference in PD-L1 expression in the TME between these two groups (60.0 vs. $10.0 \%$; $\mathrm{P}=0.017)$. IPIs $<3$ and $\geq 3$ were identified in $16(53.3 \%)$ and 14 $(46.7 \%)$ patients, respectively. PD-L1 expression on tumor cells was significantly higher in patients with an IPI $<3$ compared with patients with an IPI $\geq 3$ (87.5 vs. $42.9 \%$; $\mathrm{P}=0.019)$; however, there was no significant difference in PD-L1 expression in the TME between these two groups (50.0 vs. $35.7 \%$; $\mathrm{P}=0.484)$. According to the postoperative pathological results, $9(47.4 \%)$ patients had a GCB subtype, and 10 (52.6\%) patients had a non-GCB subtype. No significant differences were observed between the subtypes in terms of PD-L1 expression on tumor cells or in the TME ( $\mathrm{P}=0.35$ and 0.65 , respectively). In addition, age, laterality, B symptoms, LDH level, $\beta 2-M G$ level and BCL-2 expression were not significantly associated with PD-L1 expression on either tumor cells or in the TME (Table III).

Association of PD-L1 expression with PFS and OS. The median follow-up time after orchiectomy was 23.5 months (range, 2-143 months). During this time, 10 (33.3\%) patients experienced disease progression, and $11(36.7 \%)$ patients succumbed. A Kaplan-Meier analysis indicated that PD-L1 expression on tumor cells was not associated with PFS $(\mathrm{P}=0.763)$ or OS $(\mathrm{P}=0.531$; Fig. $3 \mathrm{~A}$ and $\mathrm{B})$ and that $\mathrm{PD}-\mathrm{L} 1$ expression in the TME was not associated with PFS $(\mathrm{P}=0.572)$ or $\mathrm{OS}(\mathrm{P}=0.934$; Fig. $3 \mathrm{C}$ and D). Following division of the patients into subgroups (GCB subtype and non-GCB subtype), a Kaplan-Meier analysis revealed that PD-L1 expression was not associated with PFS or OS in the GCB subtype subgroup or in the non-GCB subtype subgroup (Fig. S1). Following division of the patients into subgroups according to BCL-2 expression, a Kaplan-Meier analysis also revealed that PD-L1 expression was not associated with PFS or OS in the subgroups with BCL-2 expression scores of 0-1 and BCL-2 expression scores of 2-3 (Fig. S2). However, the Kaplan-Meier analysis demonstrated that an early stage of disease was associated with longer PFS $(\mathrm{P}=0.019)$ and OS ( $\mathrm{P}=0.016$; Fig. $3 \mathrm{E}$ and $\mathrm{F})$. In the multivariate Cox model adjusting for clinical stage, PD-L1 expression on tumor cells or in the TME was not an independent risk factor for PFS or OS.

\section{Discussion}

Previous studies have demonstrated that PD-L1 is expressed in various types of cancer, including DLBCL, and correlates with both favorable and unfavorable prognoses $(21,22)$. In a previous study on DLBCL, PD-L1 expression on tumor cells or in the TME was reported to correlate with pathological tumor stage, grade and prognosis (17). DLBCL is the predominant histopathological type of PTL, and PD-L1 overexpression in DLBCL has been reported previously (23). Therefore, whether the clinical significance of PD-L1 expression in DLBCL can be equally applied in PT-DLBCL remains unknown and warrants further study. To the best of our knowledge, the present study is the first to investigate the association of PD-L1 expression with clinicopathological characteristics and oncological outcomes in patients with PT-DLBCL. PD-L1 can be expressed on both tumor cells and tumor-infiltrating immune cells (24). PD-L1 expression is induced endogenously by genetic aberrations or oncogenic signaling, and exogenously by cytokines secreted by immune cells (25). However, the underlying molecular mechanism of PD-L1 expression in PT-DLBCL is unclear and requires further investigation.

Of particular note is the threshold for identifying PD-L1 positivity, which has varied widely. In the present study, 5\% was used as the cut-off for PD-L1 positivity on tumor cells, and $20 \%$ as the cut-off for PD-L1 positivity in the TME, in accordance with a previous study (18). Among the 30 patients with PT-DLBCL included in the present study, $67 \%$ patients were positive for PD-L1 on tumor cells and $43 \%$ were positive for PD-L1 in the TME. To put these results into context, they were compared with those of published studies concerning PD-L1 expression in DLBCL. According to the reviewed literature, the expression rates of PD-L1 on tumor cells and in the TME fluctuated from 26 to $75 \%$ and from 30 to $66 \%$, respectively $(26,27)$. The results from the present study were comparable with those observed in previous studies. Several studies have investigated the expression of PD-L1 in DLBCL using other standards. Kiyasu et al (17) reported that the rates of positive PD-L1 expression on tumor cells and in the TME were 10.5 and $15.3 \%$ using thresholds of 30.0 and $20.0 \%$, respectively. Xing et al (28) reported that the rates of positive PD-L1 expression on tumor cells and in the TME were 16.0 and $27.0 \%$ using thresholds of 30.0 and $5.0 \%$, respectively. The higher rates of PD-L1 expression in our cohorts may be due to the nature of testicles as immunologically privileged sites, or to differences in race, sample size, antibody type, immunohistochemical detection system and experimental standards.

The results of the present study indicated that patients with an early stage of disease (stage I/II) presented with higher PD-L1 expression on tumor cells compared with those at an advanced stage (stage III/IV). The results also indicated that patients at an early (stage I/II) presented with higher PD-L1 expression in the TME than those at an advanced stage (stage III/IV). Furthermore, it was observed that patients with a low IPI presented with higher PD-L1 expression on tumor cells compared with those with a high IPI. However, no significant differences were observed in PD-L1 expression on tumor cells or in the TME between subtypes. Pollari et al (27) reported that patients with PTL with limited stage I-II disease presented with higher PD-L1 expression in the TME compared with those with advanced stage III-IV disease. Pollari et al (27) also described how PD-L1 is also expressed on tumor-infiltrating non-malignant cells, primarily macrophages, and PD-1 is expressed on tumor-infiltrating lymphocytes (TILs). The interaction of PD-L1 ${ }^{+}$macrophages and PD-1 $1^{+}$TILs may 

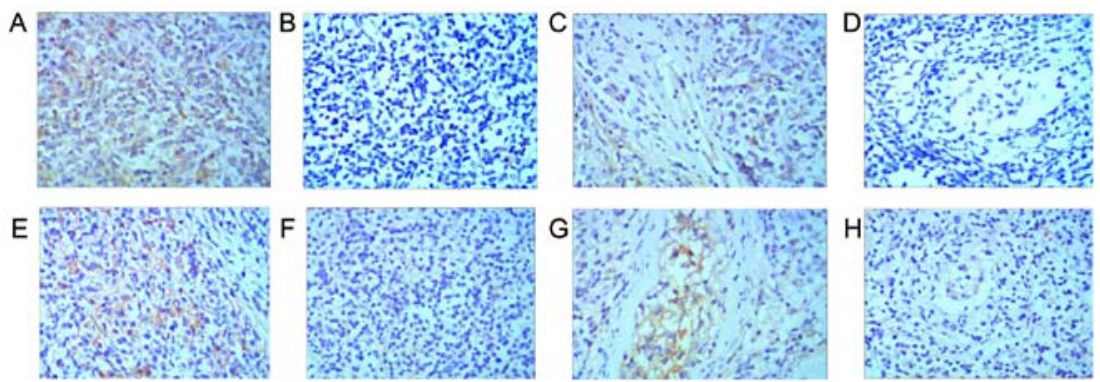

Figure 2. Immunohistochemical staining of PD-L1. (A) Positive expression and (B) lack of expression of PD-L1 in tumor cells in patients with the GCB subtype. (C) Positive expression and (D) lack of expression of PD-L1 in the TME in patients with the GCB subtype. (E) Positive expression and (F) lack of expression of PD-L1 in tumor cells in patients with the non-GCB subtype. (G) Positive expression and (H) lack of expression of PD-L1 in the TME in patients with the non-GCB subtype. Magnification, x40. PD-L1, programmed cell death ligand-1; TME, tumor microenvironment; GCB, germinal center B cell-like; non-GCB, non-germinal center B cell-like.
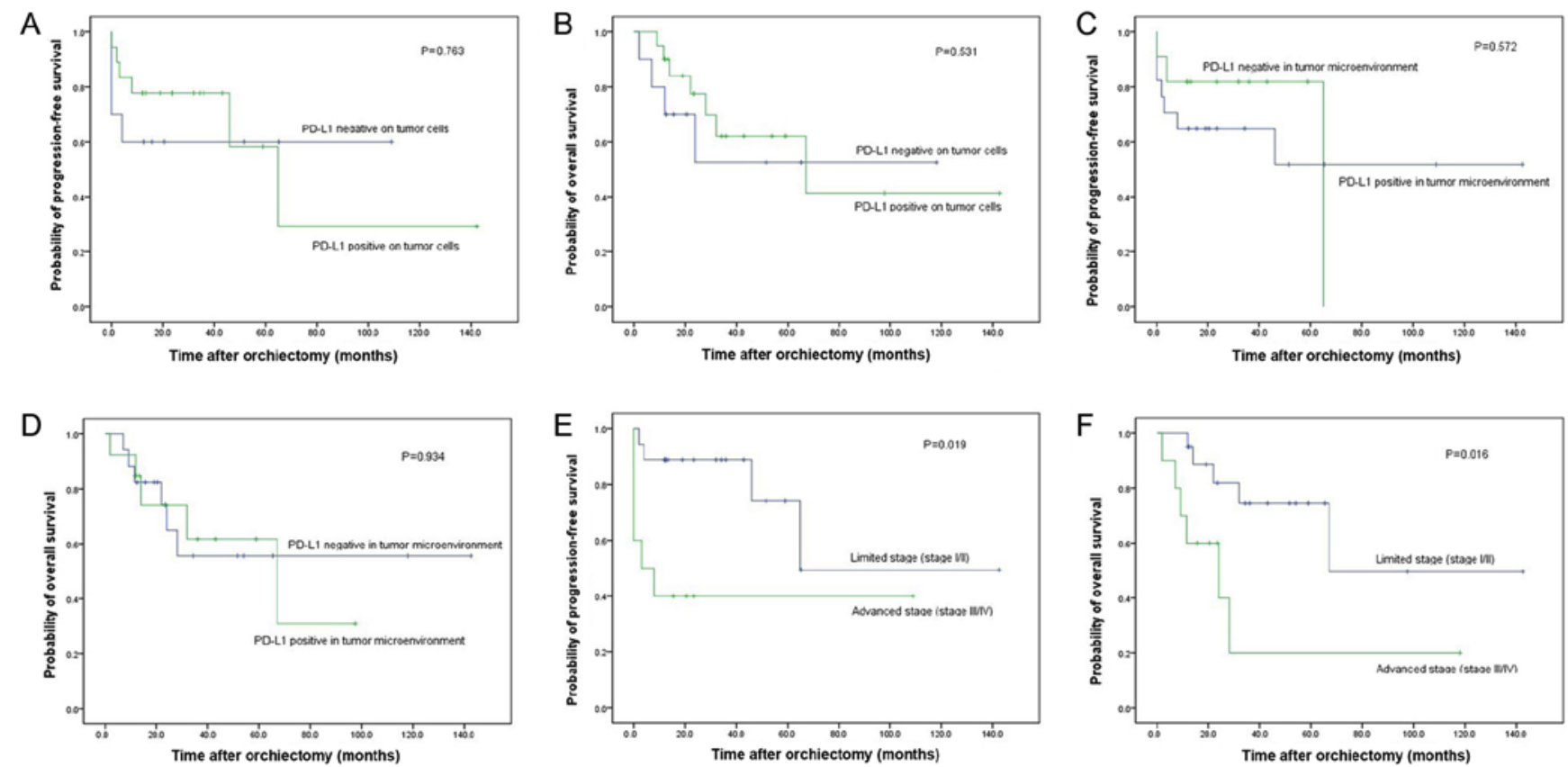

Figure 3. Association of PD-L1 expression with PFS and OS. (A) Association between PD-L1 expression on tumor cells and PFS in patients with PT-DLBCL. (B) Association between PD-L1 expression on tumor cells and OS in patients with PT-DLBCL. (C) Association between PD-L1 expression in the TME and PFS in patients with PT-DLBCL. (D) Association between PD-L1 expression in the TME and OS in patients with PT-DLBCL. (E) Association between clinical stage and PFS in patients with PT-DLBCL. (F) Association between clinical stage and OS in patients with PT-DLBCL. PFS, progression free survival; PT-DLBCL, primary testicular-diffuse large B cell lymphoma; OS, overall survival; TME, tumor microenvironment; PD-L1, programmed cell death ligand-1.

modify the TME and promote an antitumor immune response. Ishii et al (21) reported that the high expression of PD-L1 on tumor cells was correlated with an early disease stage in patients with small cell lung cancer. However, the majority of studies concerning PD-L1 expression have revealed that PD-L1 expression on tumor cells is associated with an unfavorable prognosis $(17,18,22)$. The mechanism is as follows: The PD-L1 expression on tumor cells can lead to T-cell exhaustion and a state of non-responsiveness, and can enable tumor cells to escape the immune response $(29,30)$. In PT-DLBCL, there are PD-L1-positive tumor cells, PD-L1-positive macrophages and PD-1-positive TILs, indicating that the PD-1/PD-L1 signaling pathway is much more complex (27). Nevertheless, the mechanism underlying the reciprocal effects remains unclear and requires further investigation.

To date, studies on the prognostic impact of PD-L1 expression in DLBCL have concentrated on forms of the disease other than PTL. Kiyasu et al (17) were the first to report that PD-L1 expression on tumor cells is associated with a shorter OS in patients with DLBCL. Hu et al (18) reported that PD-L1 expression predicts poor survival in patients with DLBCL in China. However, the present study did not identify that PD-L1 expression in tumor cells or in the TME was associated with PFS or OS in patients with PT-DLBCL.

There are several limitations to the present study. First, this was a single-center retrospective study with a small sample size of 30 patients; therefore, prospective studies with more patients are warranted to validate the status and prognostic value of PD-L1 expression in patients with PT-DLBCL. Secondly, immunohistochemistry is a semiquantitative technique and is influenced by multiple factors, such as antibody concentrations and cut-off criteria. However, positive and negative control slides were used in the present study to ensure the reliability of the protocol used. Thirdly, because the ideal 
Table III. Association between PD-L1 expression and clinicopathological characteristics in 30 patients with primary testicular diffuse large B cell lymphoma.

\begin{tabular}{|c|c|c|c|c|c|c|}
\hline \multirow[b]{2}{*}{ Features } & \multicolumn{2}{|c|}{$\begin{array}{l}\text { PD-L1 expression } \\
\text { in tumor cells, } \mathrm{n}\end{array}$} & \multirow[b]{2}{*}{ P-value } & \multicolumn{2}{|c|}{$\begin{array}{l}\text { PD-L1 expression in } \\
\text { tumor microenvironment, } \mathrm{n}\end{array}$} & \multirow[b]{2}{*}{ P-value } \\
\hline & Negative & Positive & & Negative & Positive & \\
\hline Age, years & & & 0.694 & & & $>0.999$ \\
\hline$\leq 60$ & 3 & 9 & & 7 & 5 & \\
\hline$>60$ & 7 & 11 & & 10 & 8 & \\
\hline Laterality & & & 0.127 & & & 0.733 \\
\hline Left & 7 & 7 & & 9 & 5 & \\
\hline Right & 3 & 9 & & 6 & 6 & \\
\hline Bilateral & 0 & 4 & & 2 & 2 & \\
\hline B symptoms & & & 0.584 & & & 0.113 \\
\hline No & 8 & 18 & & 13 & 13 & \\
\hline Yes & 2 & 2 & & 4 & 0 & \\
\hline $\mathrm{LDH}^{\mathrm{a}}, \mathrm{U} / 1$ & & & 0.262 & & & $>0.999$ \\
\hline$\leq 245$ & 5 & 10 & & 7 & 8 & \\
\hline$>245$ & 0 & 6 & & 3 & 3 & \\
\hline$\beta 2-\mathrm{MG}^{\mathrm{b}}, \mathrm{mg} / \mathrm{l}$ & & & $>0.999$ & & & $>0.999$ \\
\hline$\leq 2.52$ & 2 & 6 & & 4 & 4 & \\
\hline$>2.52$ & 2 & 3 & & 3 & 2 & \\
\hline Clinical stage & & & 0.045 & & & 0.017 \\
\hline I-II & 4 & 16 & & 8 & 12 & \\
\hline III-IV & 6 & 4 & & 9 & 1 & \\
\hline IPI & & & 0.019 & & & 0.484 \\
\hline$<3$ & 2 & 14 & & 8 & 8 & \\
\hline$\geq 3$ & 8 & 6 & & 9 & 5 & \\
\hline GCB subtype ${ }^{c}$ & & & 0.35 & & & 0.650 \\
\hline Non-GCB & 2 & 8 & & 5 & 5 & \\
\hline GCB & 4 & 5 & & 6 & 3 & \\
\hline BCL-2 score ${ }^{\mathrm{d}}$ & & & $>0.999$ & & & 0.315 \\
\hline $0-1$ & 3 & 6 & & 3 & 6 & \\
\hline $2-3$ & 2 & 4 & & 4 & 2 & \\
\hline
\end{tabular}

${ }^{a}$ The data of 9 patients were missing; b the data of 17 patients were missing; "cthe data of 11 patients were missing; ${ }^{d}$ the data of 15 patients were missing. PT-DLBCL, primary testicular diffuse large B cell lymphoma; LDH, lactate dehydrogenase; $\beta 2$-MG, $\beta_{2}$-microglobulin; GCB, germinal center B cell-like; BCL-2, B cell leukemia 2; IPI, International Prognostic Index. B symptoms were defined as unexplained fever, drenching night sweats and weight loss $>10 \%$ of normal body weight.

treatment for PTL-DLBCL remains under debate, the patients in the present study received a variety of treatments, which made it difficult to identify relevant prognostic factors.

In conclusion, PD-L1 is differentially expressed in tumor cells and in the TME in PT-DLBCL. No significant association was identified with age, laterality, B symptoms, LDH, $\beta 2-\mathrm{MG}$, GCB subtype or BCL-2 expression. However, PD-L1 expression in tumor cells and in the TME was higher in patients at an early stage of disease compared with in those at an advanced stage, and PD-L1 expression on tumor cells was higher in patients with a low IPI compared with those with a high IPI. Furthermore, PD-L1 expression on tumor cells and in the TME was not associated with PFS or OS.

\section{Acknowledgements}

Not applicable.

\section{Funding}

No funding was received.

\section{Availability of data and materials}

The datasets used and analyzed during the present study are available from the corresponding author upon reasonable request. 


\section{Authors' contributions}

CS, WY and JJ designed the study and revised the manuscript. DDZ, JZ and PH contributed to the writing of the manuscript and analyzing the patient data. YF contributed to the collection and analysis of the data. JL and QH contributed to the assessment of PD-L1 expression. WKH and ZYZ designed the study and revised the manuscript critically for important intellectual content. All authors read and approved the final manuscript.

\section{Ethics approval and consent to participate}

The study was approved by the Ethics Committee of Peking University First Hospital (ethics no., 2018 [197]). A waiver of written informed consent was granted from the Ethics Committee of Peking University First Hospital.

\section{Patient consent for publication}

Not applicable.

\section{Competing interests}

The authors declare that they have no competing interests.

\section{References}

1. Kemal Y, Teker F, Demirag G and Yucel I: Primary testicular lymphoma: A single centre experience. Exp Oncol 37: 223-226, 2015.

2. Vitolo U, Ferreri AJ and Zucca E: Primary testicular lymphoma. Crit Rev Oncol Hematol 65: 183-189, 2008.

3. Møller MB, d'Amore F and Christensen BE: Testicular lymphoma: a population-based study of incidence, clinicopathological correlations and prognosis The Danish Lymphoma Study Group, LYFO. Eur J Cancer 30A: 1760-1764, 1994.

4. Zucca E, Conconi A, Mughal TI, Sarris AH, Seymour JF, Vitolo U, Klasa R, Ozsahin M, Mead GM, Gianni MA, et al Patterns of outcome and prognostic factors in primary large-cell lymphoma of the testis in a survey by the International Extranodal Lymphoma Study Group. J Clin Oncol 21: 20-27, 2003.

5. Dong Y, Sun Q and Zhang X: PD-1 and its ligands are important immune checkpoints in cancer. Oncotarget 8: 2171-2186, 2017.

6. Goodman A, Patel SP and Kurzrock R: PD-1-PD-L1 immune-checkpoint blockade in B-cell lymphomas. Nat Rev Clin Oncol 14: 203-220, 2017.

7. Chen BJ, Chapuy B, Ouyang J, Sun HH, Roemer MG, Xu ML, Yu H, Fletcher CD, Freeman GJ, Shipp MA and Rodig SJ: PD-L1 expression is characteristic of a subset of aggressive B-cell lymphomas and virus-associated malignancies. Clin Cancer Res 19: 3462-3473, 2013.

8. Francisco LM, Sage PT and Sharpe AH: The PD-1 pathway in tolerance and autoimmunity. Immunol Rev 236: 219-242, 2010.

9. Freeman GJ, Long AJ, Iwai Y, Bourque K, Chernova T, Nishimura H, Fitz LJ, Malenkovich N, Okazaki $T$, Byrne MC, et al: Engagement of the PD-1 immunoinhibitory receptor by a novel $\mathrm{B} 7$ family member leads to negative regulation of lymphocyte activation. J Exp Med 192: 1027-1034, 2000.

10. Topalian SL, Hodi FS, Brahmer JR, Gettinger SN, Smith DC, McDermott DF, Powderly JD, Carvajal RD, Sosman JA, Atkins MB, et al: Safety, activity, and immune correlates of anti-PD-1 antibody in cancer. N Engl J Med 366: 2443-2454, 2012.

11. Bachy E and Coiffier B: Anti-PDI antibody: A new approach to treatment of lymphomas. Lancet Oncol 15: 7-8, 2014

12. Ansell SM, Lesokhin AM, Borrello I, Halwani A, Scott EC, Gutierrez M, Schuster SJ, Millenson MM, Cattry D, Freeman GJ, et al: PD-1 blockade with nivolumab in relapsed or refractory Hodgkin's lymphoma. N Engl J Med 372: 311-319, 2015.
13. Dunn GP, Bruce AT, Ikeda H, Old LJ and Schreiber RD: Cancer immunoediting: From immunosurveillance to tumor escape. Nat Immunol 3: 991-998, 2002.

14. Cheah CY, Wirth A and Seymour JF: Primary testicular lymphoma. Blood 123: 486-493, 2014

15. Merryman RW, Armand P, Wright KT and Rodig SJ: Checkpoint blockade in Hodgkin and non-Hodgkin lymphoma. Blood Adv 1: 2643-2654, 2017.

16. Menter T, Ernst M, Drachneris J, Dirnhofer S, Barghorn A, Went $P$ and Tzankov A: Phenotype profiling of primary testicular diffuse large B-cell lymphomas. Hematol Oncol 32: 72-81, 2014.

17. Kiyasu J, Miyoshi H, Hirata A, Arakawa F, Ichikawa A, Niino D, Sugita Y, Yufu Y, Choi I, Abe Y, et al: Expression of programmed cell death ligand 1 is associated with poor overall survival in patients with diffuse large B-cell lymphoma. Blood 126: 2193-2201, 2015.

18. Hu LY, Xu XL, Rao HL, Chen J, Lai RC, Huang HQ, Jiang WQ, Lin TY, Xia ZJ and Cai QQ: Expression and clinical value of programmed cell death-ligand 1 (PD-L1) in diffuse large B cell lymphoma: A retrospective study. Chin J Cancer 36: 94, 2017.

19. Hans CP, Weisenburger DD, Greiner TC, Gascoyne RD, Delabie J, Ott G, Müller-Hermelink HK, Campo E, Braziel RM, Jaffe ES, et al: Confirmation of the molecular classification of diffuse large B-cell lymphoma by immunohistochemistry using a tissue microarray. Blood 103: 275-282, 2004.

20. Gascoyne RD, Adomat SA, Krajewski S, Krajewska M, Horsman DE, Tolcher AW, O'Reilly SE, Hoskins P, Coldman AJ, Reed JC and Connors JM: Prognostic significance of Bcl-2 protein expression and $\mathrm{Bcl}-2$ gene rearrangement in diffuse aggressive non-Hodgkin's lymphoma. Blood 90: 244-251, 1997.

21. Ishii H, Azuma K, Kawahara A, Yamada K, Imamura Y, Tokito T, Kinoshita T, Kage M and Hoshino T: Significance of programmed cell death-ligand 1 expression and its association with survival in patients with small cell lung cancer. J Thorac Oncol 10: 426-430, 2015.

22. Zhang B, Yu W, Feng X, Zhao Z, Fan Y, Meng Y, Hu S, Cui Y, He Q, Zhang H, et al: Prognostic significance of PD-L1 expression on tumor cells and tumor-infiltrating mononuclear cells in upper tract urothelial carcinoma. Med Oncol 34: 94, 2017.

23. Georgiou K, Chen L, Berglund M, Ren W, de Miranda NF, Lisboa S, Fangazio M, Zhu S, Hou Y, Wu K, et al: Genetic basis of PD-L1 overexpression in diffuse large B-cell lymphomas. Blood 127: 3026-3034, 2016.

24. Andorsky DJ, Yamada RE, Said J, Pinkus GS, Betting DJ and Timmerman JM: Programmed death ligand 1 is expressed by non-hodgkin lymphomas and inhibits the activity of tumor-associated T cells. Clin Cancer Res 17: 4232-4244, 2011.

25. Kwon D, Kim S, Kim PJ, Go H, Nam SJ, Paik JH, Kim YA, Kim TM, Heo DS, Kim CW and Jeon YK: Clinicopathological analysis of programmed cell death-1 and programmed cell death-ligand 1 expression in the tumor microenvironments of diffuse large B-cell lymphomas. Histopathology 68: 1079-1089, 2016.

26. Xu-Monette ZY, Zhou J and Young KH: PD-1 expression and clinical PD-1 blockade in B-cell lymphomas. Blood 131: 68-83, 2018.

27. Pollari $M$, Brück $O$, Pellinen $T$, Vähämurto $P$, Karjalainen-Lindsberg ML, Mannisto S, Kallioniemi O, Kellokumpu-Lehtinen PL, Mustjoki S, Leivonen SK and Leppä S: PD-L1+ tumor-associated macrophages and PD-1+ tumor infiltrating lymphocytes predict survival in primary testicular lymphoma. Haematologica 103: 1908-1914, 2018.

28. Xing W, Dresser K, Zhang R, Evens AM, Yu H, Woda BA and Chen BJ: PD-L1 expression in EBV-negative diffuse large B-cell lymphoma: Clinicopathologic features and prognostic implications. Oncotarget 7: 59976-59986, 2016.

29. Wherry EJ and Kurachi M: Molecular and cellular insights into T cell exhaustion. Nat Rev Immunol 15: 486-499, 2015.

30. Pauken KE and Wherry EJ: Overcoming T cell exhaustion in infection and cancer. Trends Immunol 36: 265-276, 2015.

This work is licensed under a Creative Commons Attribution-NonCommercial-NoDerivatives 4.0 International (CC BY-NC-ND 4.0) License. 